\title{
EPIDEMIOLOGICAL ANALYSIS OF GRANULOMATOUS MASTITIS AT THE MASTOLOGY SERVICE AT HOSPITAL MATERNO INFANTIL DE GOIÂNIA
}

Aline R. Nunes ${ }^{1}$, Célio S. R. Vidal², Délio M. Conde², Erika P. S. Silva ${ }^{2,3,4}$, Flávia V. Cabero1 , Gustavo L. Q. Lima ${ }^{1}$, Rogério B. Ferreira ${ }^{2,3}$, Paola F. Freitas ${ }^{5}$

${ }^{1}$ Hospital Geral de Goiânia - Goiânia (GO), Brazil.

${ }^{2}$ Mastology Service, Hospital Materno Infantil de Goiânia - Goiânia (GO), Brazil.

${ }^{3}$ Mastology Service, Hospital Geral de Goiânia - Goiânia (GO), Brazil.

${ }^{4}$ Mastology Department, Hospital Geral de Goiânia - Goiânia (GO), Brazil.

${ }^{5}$ Maternidade Municipal Aristina Cândida - Senador Canedo (GO), Brazil.

Objectives: The present study aims to evaluate the patient's profile, along with ways of diagnosing granulomatous mastitis (GM) disease, duration of treatment, remission and relapse time. Methodology: A retrospective analysis of physical records of patients treated between January 2010 and October 2017, at Hospital Materno Infantil de Goiânia. Results: During this time, ten women were diagnosed and treated for GM. All women underwent clinical breast examination to identify palpable tumors. Ultrasonography was the initial imaging method used for the evaluation, however mammography was performed in three cases due to the screening age range for breast cancer. The definitive diagnosis was obtained by core biopsy or surgical excision, with histopathological result confirming GM. The median age was 36.1 years. As for the use of oral contraceptive, the mean time of use was 5.5 years, and only one patient did not report the use of it. Only one patient was nulliparous, the others had been pregnant at least once, with an average time of breastfeeding of 1.5 years and all had interrupted it for more than two years. Two patients had diabetes mellitus, one of whom was diagnosed during the investigation of the GM. The most common symptoms were pain (90\%), breast masses (80\%) and association with abscess (60\%). Three patients used antibiotics because of the association of abscess infections with the inflammatory process of mastitis. Nine patients have used corticosteroids to treat the disease since diagnosis. The only patient with abscess drainage, quadrantectomy and antibiotic therapy was also the only one that present with local recurrence two months after treatment, and remission was achieved after using corticotherapy. Regarding treatment with corticosteroids, dose reduction was done according to clinical response. The mean time of treatment was 3.1 months [1-7 months], and mean follow-up time of the patients was 24.8 months [9-96 months]. Conclusion: The study presents the same epidemiology, follow-up time and treatment response in accordance with international literature. Implementing a flow chart of care, diagnosis, therapy and follow-up of GM improves the quality and assertiveness of early treatment, avoiding misuse of antibiotics. 